\title{
Development and Testing of High Performance Nylon12 (PA12) Based Natural Fiber Composites
}

\author{
Siddhartha Brahma*, Garo Tritrian, Selvum Pillay, Na Lu, Haibin Ning \\ ${ }^{1}$ Department of Materials Science and Engineering, University of Alabama at Birmingham, Birmingham, AL 35294, USA \\ ${ }^{2}$ Department of Civil Engineering, Purdue University, West Lafayette, IN 47907, USA
}

Received August 3, 2020; Revised November 18, 2020; Accepted November 29, 2020

\section{Cite This Paper in the following Citation Styles}

(a): [1] Siddhartha Brahma, Garo Tritrian, Selvum Pillay, Na Lu, Haibin Ning, "Development and Testing of High Performance Nylon12 (PA12) Based Natural Fiber Composites," Universal Journal of Materials Science, Vol. 8, No. 3, pp. 45 - 55, 2020. DOI: 10.13189/ujms.2020.080301.

(b): Siddhartha Brahma, Garo Tritrian, Selvum Pillay, Na Lu, Haibin Ning (2020). Development and Testing of High Performance Nylon12 (PA12) Based Natural Fiber Composites. Universal Journal of Materials Science, 8(3), 45 - 55. DOI: 10.13189/ujms.2020.080301.

Copyright $\mathrm{C} 2020$ by authors, all rights reserved. Authors agree that this article remains permanently open access under the terms of the Creative Commons Attribution License 4.0 International License

\begin{abstract}
Kenaf based nylon 12 (PA12) composites were successfully made using hydroentanglement and film stack compression molding. The combination of natural fibers with an engineering polymer with a relatively low melting temperature can potentially have high strength and modulus composites. The chopped kenaf fibers were treated in a $\mathrm{NaOH}$ solution. The $\mathrm{NaOH}$ treatment is used to improve the roughness of the surface and also expose cellulose fibers within the fibers to help improve bonding with the resin. Tensile tests of samples with treated and untreated fibers with a fiber weight fraction of $40 \%$ show that the treated fiber composite has an improvement of $13 \%$ and $18 \%$ in its strength and modulus respectively. The resulting fibers were used to make preforms using hydroentanglement process. The process of hydroentanglement is typically used in making paper products. The use of this process to make composite materials using chopped fibers is a very unique approach adopted for this research. Three different fiber weight fractions were looked at namely $40 \%, 50 \%$ and $60 \%$. Tensile and flexure testing of the samples showed a consistent increase with an increase in the fiber weight fraction. Morphological characterization of the fibers showed that treatment removed excess fluff and dirt and also had striations on the fiber which would lead to better fiber wet-out. SEM images of the fractured surface of the sample with $50 \%$ by weight of kenaf fibers showed that there was some fiber bundling as expected leading to dry zones within the composite which could potentially lead to crack initiation. The novelty of the research is developing preforms using chopped natural fibers using
\end{abstract}

hydroentanglement process and the ability to combine these natural fibers with low melting point PA 12 leading to obtaining high strength composite without compromising the structural integrity of the kenaf fibers.

Keywords Kenaf, Nylon 12, Hydroentanglement, Compression Molding, Natural Fiber, Mechanical

\section{Introduction}

Composite materials are a unique class of materials that have a heterogeneous combination of a matrix and reinforcement to provide tailored properties for applications. While the market is still predominately thermoset driven, there has been a steady growth in the use of thermoplastics in many industries such as mass transportation, automotive, sporting and utility industries [1]. Thermoplastics, due to their superior toughness and recyclability, as compared to thermosets, are playing a major role in producing sustainable products [2]. While there are a range of reinforcements, most of which are synthetic, in recent years there have been an increase in the use of natural fibers as reinforcements.

Natural fibers have been used extensively in the textile fabric and the cottage industry all over the world as documented in studies showing production of natural fibers in different countries [3-5]. The main advantages of natural fibers are that they are eco-friendly and essentially a renewable source. The main disadvantage with them is their high moisture uptake and the variability in the fiber's 
inherent properties which stems from the extraction of the fibers from the bast $[3,6,7]$. The process of retting can be done using various methods such as chemical, water based etc. and this in turn affects the final mechanical properties of the fibers obtained $[4,8]$.

There have been several studies looking at polypropylene or polyethylene based natural fiber composites. But when it comes to using engineering plastics, due to their higher melting temperature, cannot be used with natural fibers without compromising the fibers structural properties. Natural fibers have a degradation temperature around $200^{\circ} \mathrm{C}[6,9,10]$. At this temperature, most engineering thermoplastics are eliminated. TGA analysis of the fibers has also shown a significant weight loss between $220^{\circ} \mathrm{C}$ and $330^{\circ} \mathrm{C}$ [11]. While there are many natural fibers that are used, the most viable ones due to their superior mechanical properties are kenaf, jute, sisal and hemp which are bast based fibers [4].

There have been several studies looking at hemp, flax, jute, sisal and bamboo. One of the more interesting fibers which has good mechanical properties is kenaf. Kenaf is a fast growing plant, typically 3 months after planting a seed, and can grow in many weather conditions [12]. It is used mainly in the paper and cottage industry. Many studies have been conducted on its chemical makeup and its inherent mechanical properties $[8,13]$. Studies show that kenaf fibers have a strength around $930 \mathrm{MPa}$ and a tensile modulus of around $53 \mathrm{GPa}$ [13]. This makes kenaf a good candidate to combine with thermoplastics to make secondary and tertiary structural components.

While most engineering plastics have a high melting point due to their monomer makeup and bulky side groups, Nylon 12 (PA12) is an interesting thermoplastic to use with natural fibers. With a melting temperature around $180^{\circ} \mathrm{C}$, and a water absorption rate significantly lower than nylon 6 (PA6) and nylon 6,6 (PA6,6), PA12 offers a unique set of processing conditions as compared to other polyamides. It has relatively good mechanical properties with a tensile modulus of $1.7 \mathrm{GPa}$ and a tensile strength of $48 \mathrm{MPa}$ [14].

One of the drawbacks of using discontinuous fiber preforms in film stacking is the upper limit of the fiber weight fraction that can be used. Several studies have shown that there is a significant drop in properties due to inadequate bonding between the fibers and resin at weight fractions above $50 \%$ to $60 \%$ for fiber preforms made using hydroentanglement [21 - 24].

The main objective of this study is to process chopped and treated kenaf fiber PA12 based composites with various fiber weight fractions to study their mechanical properties. Thermal analysis will be conducted on the polymer to ascertain its melting point for processing. Morphological analysis will be done on the fractured surface to study the failure mode for the composites. The unique process of using hydroentanglement to produce preforms of chopped and treated kenaf fibers for film stack compression molding is an innovative approach to make natural fiber composites. This process offers a cost effective and efficient option to produce well distributed discontinuous natural fiber preforms to be used for film stacked compression molding.

\section{Materials and Methodology}

The kenaf fibers used for the process were discontinuous fibers obtained from Ceto Tech. The fibers were $1 " \pm 0.25$ " in length. The density of the fibers was $1.51 \mathrm{~g} / \mathrm{cm}^{3}$. The tensile strength and modulus of the fibers were $400 \pm 42$ $\mathrm{MPa}$ and $53 \pm 0.9 \mathrm{GPa}$ respectively. The nylon (PA12) was obtained in film form from Goodfellow. The film had dimensions of $150 \mathrm{~mm}$ by $150 \mathrm{~mm}$ with a thickness of 0.05 $\mathrm{mm}$. The density of the PA12 was $1.02 \mathrm{~g} / \mathrm{cm}^{3}$. Its tensile strength and modulus were $45 \pm 2.5 \mathrm{MPa}$ and $1.61 \pm 0.14$ GPa. The advantage of PA12 as compared to more commonly used PA6 is its lower melting point of around $180^{\circ} \mathrm{C}$ as compared to PA6 $\left(\sim 227^{\circ} \mathrm{C}\right)$. Another advantage is its lower water and moisture uptake which is reported as significantly lower than of PA6. Differential Scanning Calorimetry (DSC) analysis was carried out on the film to get the melting point of the material. The data attained from DSC are shown in figure 1.

The sample used for the DSC was dried in an oven at $60^{\circ} \mathrm{C}$ for 6 hours. The general conditions of the testing was in a nitrogen environment with a ramp up rate of $10^{\circ} \mathrm{C} / \mathrm{min}$. The melting point for PA12 based on the data is $178^{\circ} \mathrm{C}$. This is advantageous as studies have shown that natural fibers or fibers with high cellulo- lignin content degrade at $200^{\circ} \mathrm{C}[6]$.

The kenaf fibers were treated prior to making the composite. Chemical treatment is the most commonly used method for treating natural fibers. The main objective is to use agents that contain groups which are capable of forming bonds with the hydroxyl group in the fibers. The most common agent used for the chemical treatment of natural fibers is sodium hydroxide $(\mathrm{NaOH})$ [15-17]. The fibers were first cleaned with water and then placed in 5\% wt. $\mathrm{NaOH}$ solution at $50^{\circ} \mathrm{C}$ for 24 hours. The fibers were then cleaned repeatedly with water to bring the $\mathrm{pH}$ of the fibers down to 7 to ensure all the base stuck on the fibers was completely washed [15]. The main reason for this treatment is to increase fiber surface roughness and subsequently expose cellulose thus increasing potential reaction sites for better bonding with the matrix [18-20]. Scanning Electron Microscope (SEM) images of the fibers before and after treatment are shown in figure 2. The images are obtained at a magnification of $1500 \mathrm{x}$ in a low vacuum chamber. The images show that the surface of the treated fibers is significantly rougher than the untreated fibers which were expected from literature. In order to confirm that there is in fact an improvement from the alkali treatment, samples with a fiber weight fraction of $40 \%$ were prepared using the untreated and treated kenaf fibers. The results from the tensile tests for these samples are mentioned in the results and discussion sections. 


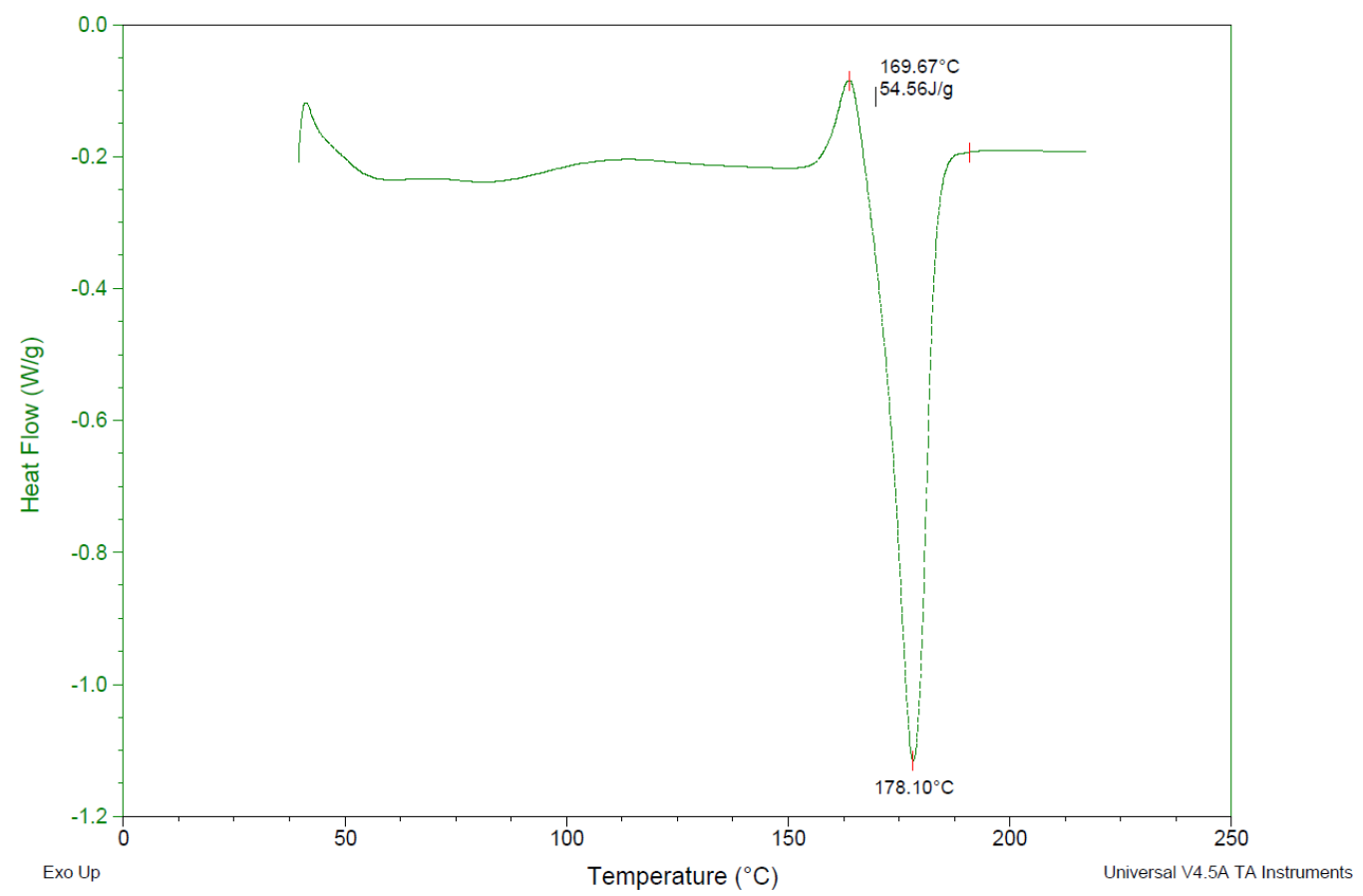

Figure 1. It shows the DSC data for PA12

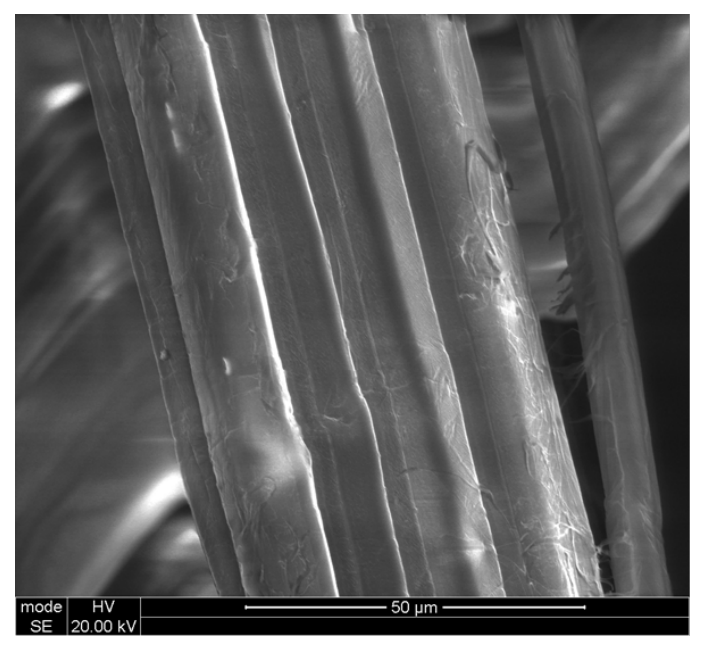

(a)

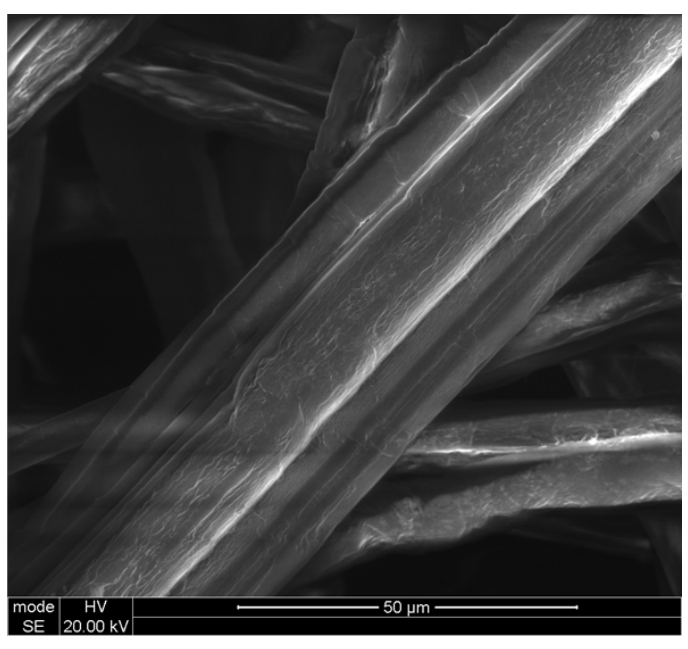

(b)

Figure 2. It shows the SEM images at 1500x for, (a) untreated kenaf fibers; (b) treated kenaf fibers 


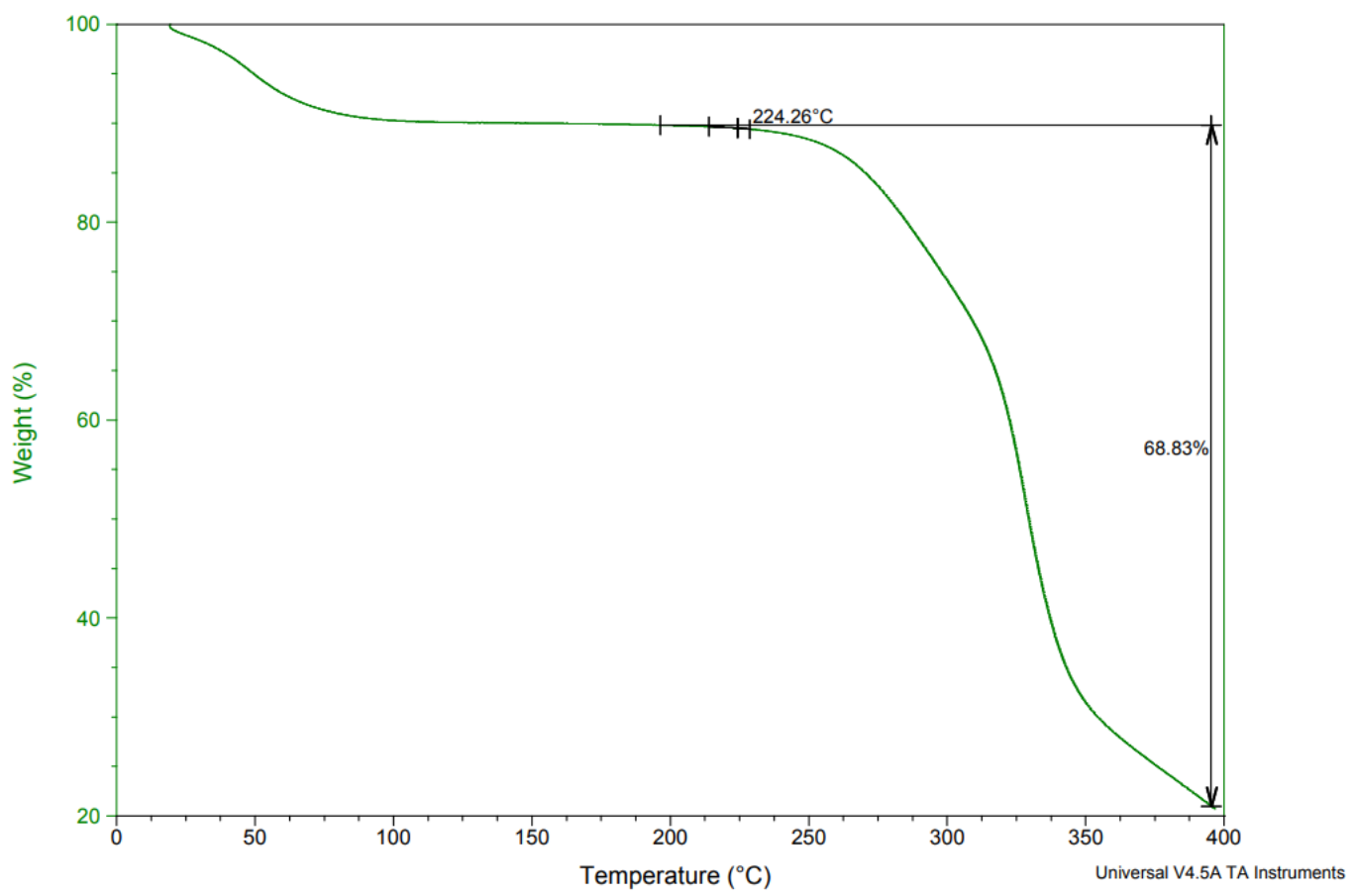

Figure 3. It shows the TGA curve for the treated kenaf fibers.

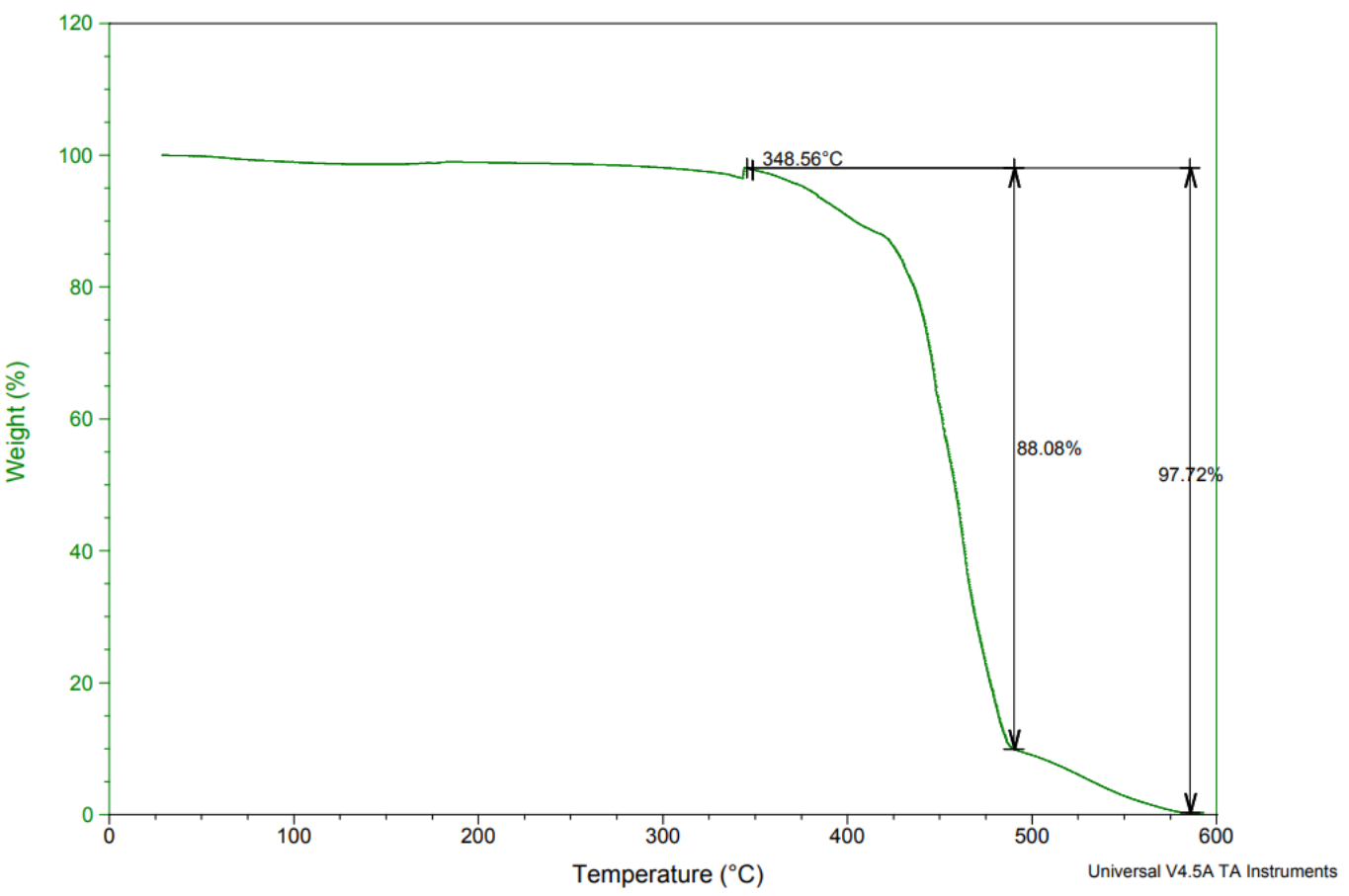

Figure 4. It shows TGA curve for the PA12 matrix

To ensure the right molding temperature was used for the processing of the fibers, TGA studies were carried out on the treated fibers and matrix in a nitrogen environment. The TGA curves for the kenaf fibers and PA12 matrix are shown in figures 3 and 4 respectively.

The fibers were not dried before running the test. This is apparent in the figure as there is an initial drop in its weight by nearly $10 \%$ corresponding to loss of water absorbed by the kenaf fibers. This stabilizes after $100{ }^{\circ} \mathrm{C}$ as the water is evaporated from the fibers. The fibers have an onset of degradation at $205^{\circ} \mathrm{C}$ and start to degrade at $224^{\circ} \mathrm{C}$ as shown in the figure. At this point there is rapid degradation of the fiber between $225^{\circ} \mathrm{C}$ and $475^{\circ} \mathrm{C}$, which is in agreement with literature. As a result, value of $185^{\circ} \mathrm{C}$ was set as the upper limit for processing as any higher would bring about the onset of degradation. 
Once the fibers are treated using $\mathrm{NaOH}$ as mentioned in the previous section, they are then made into preforms by using a process called hydroentanglement $[2,21]$. The basic setup of the process is shown in figure 5 . The treated kenaf fibers are first chopped up to about $1 " \pm 0.25$ " in length and distributed by using a shear mixer for 15 minutes in water to get a consistent distribution of fibers in the water. Once this is done, the mixture is transferred to the hydroentanglement setup as shown in the figure. Here there is an additional 10 minutes of agitation using a shear mixer. The water is then flushed out leaving behind a consolidated preform. No binder is used to hold the preforms as the processing temperature is not high enough to remove the binder. The preform is then dried in an oven at $90^{\circ} \mathrm{C}$ for 8 hours till all the excess water is removed from the preform. During this 8 hour period, the preform is weighed every 2 hours to note the difference in its weight from loss of moisture. The preforms are removed from the drier and stored once the change in its weight is less than $0.5 \%$.

Prior to processing, the preforms are again re-dried at $80^{\circ} \mathrm{C}$ for 2 hours to ensure the removal of any additional moisture uptake during storage. The dried preforms are then stacked with the PA12 film in order to attain different fiber weight fractions i.e. $40 \%, 50 \%$ and $60 \%$ by weight of fibers in the final composite. The layers of kenaf preforms and PA12 film were placed in a mold and compression molded at $185^{\circ} \mathrm{C}$ and 20 -ton pressure. A dwell time of 30 mins was used at this final temperature and pressure. The mold was then air cooled to room temperature and composite panel was removed from the tool. The panels were then measured and cut to various specimens for mechanical characterization.

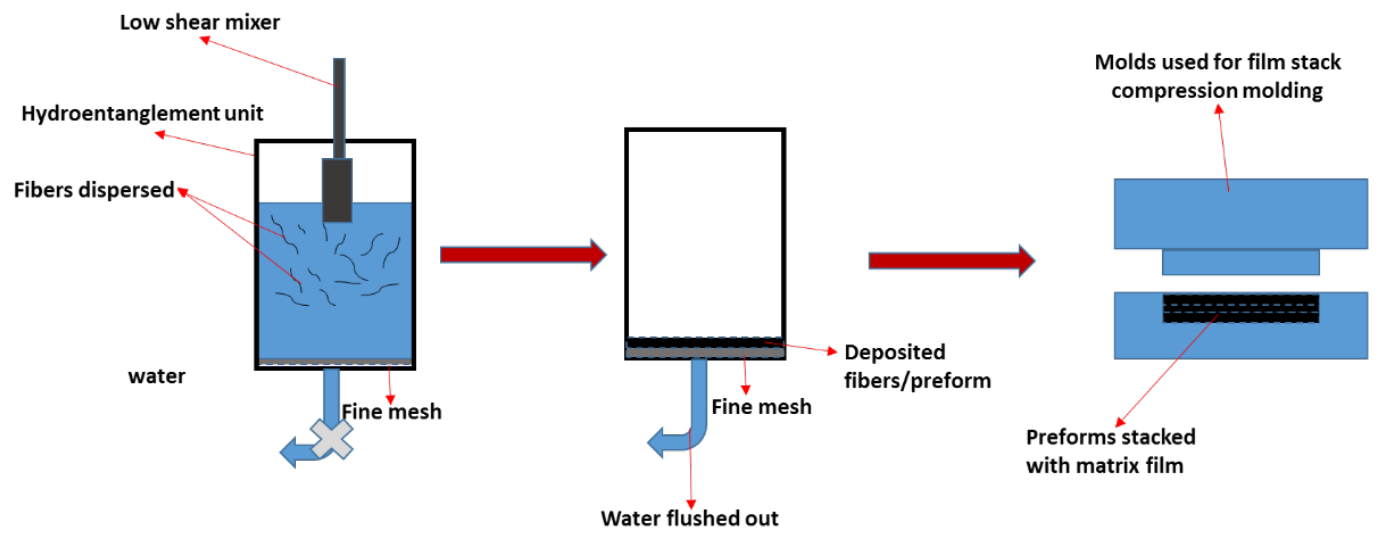

Figure 5. It shows the setup for hydroentanglement and compression molding process

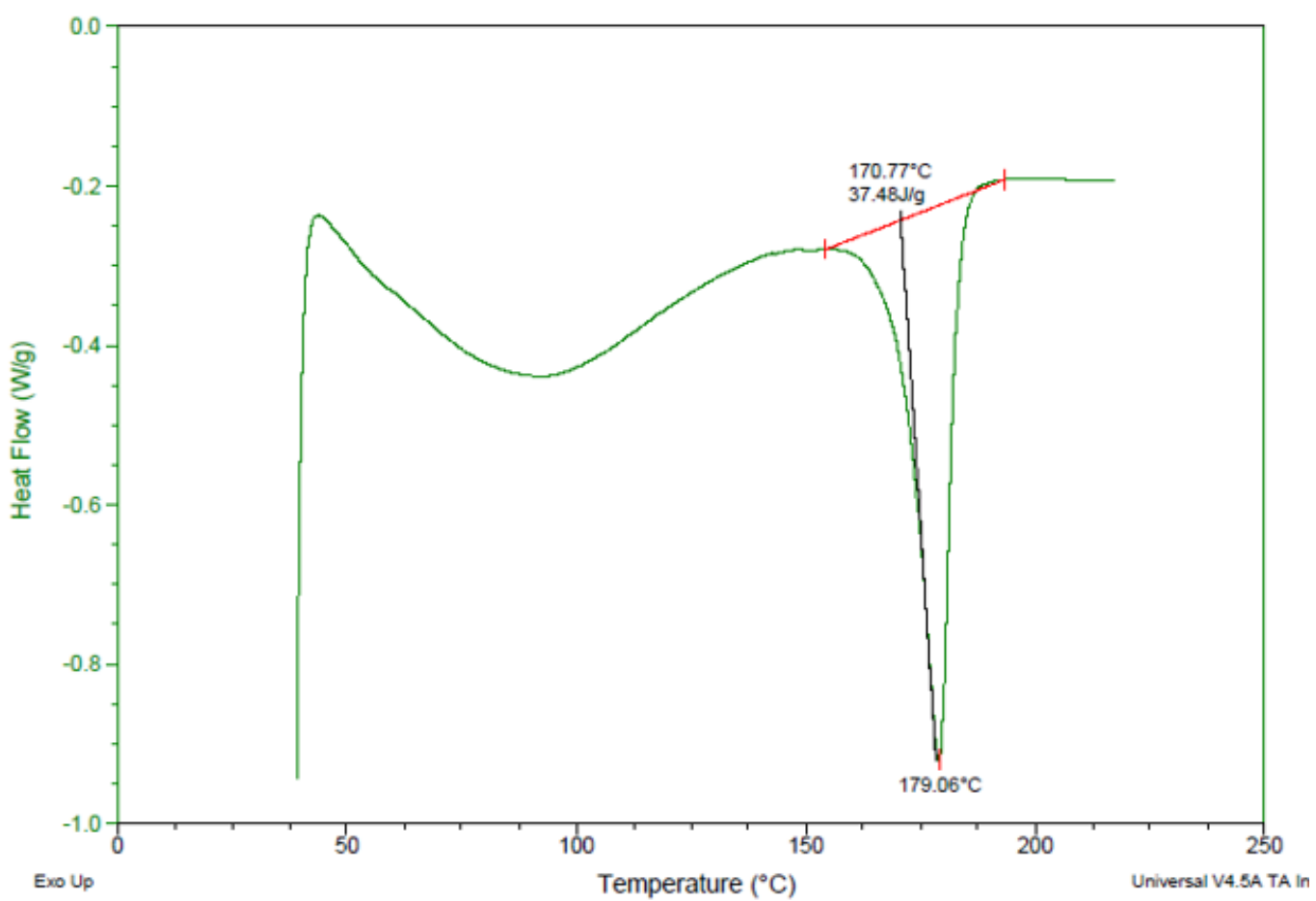

Figure 6. It shows the DSC curve for the untreated kenaf fiber composite with a fiber weight fraction of $40 \%$ 


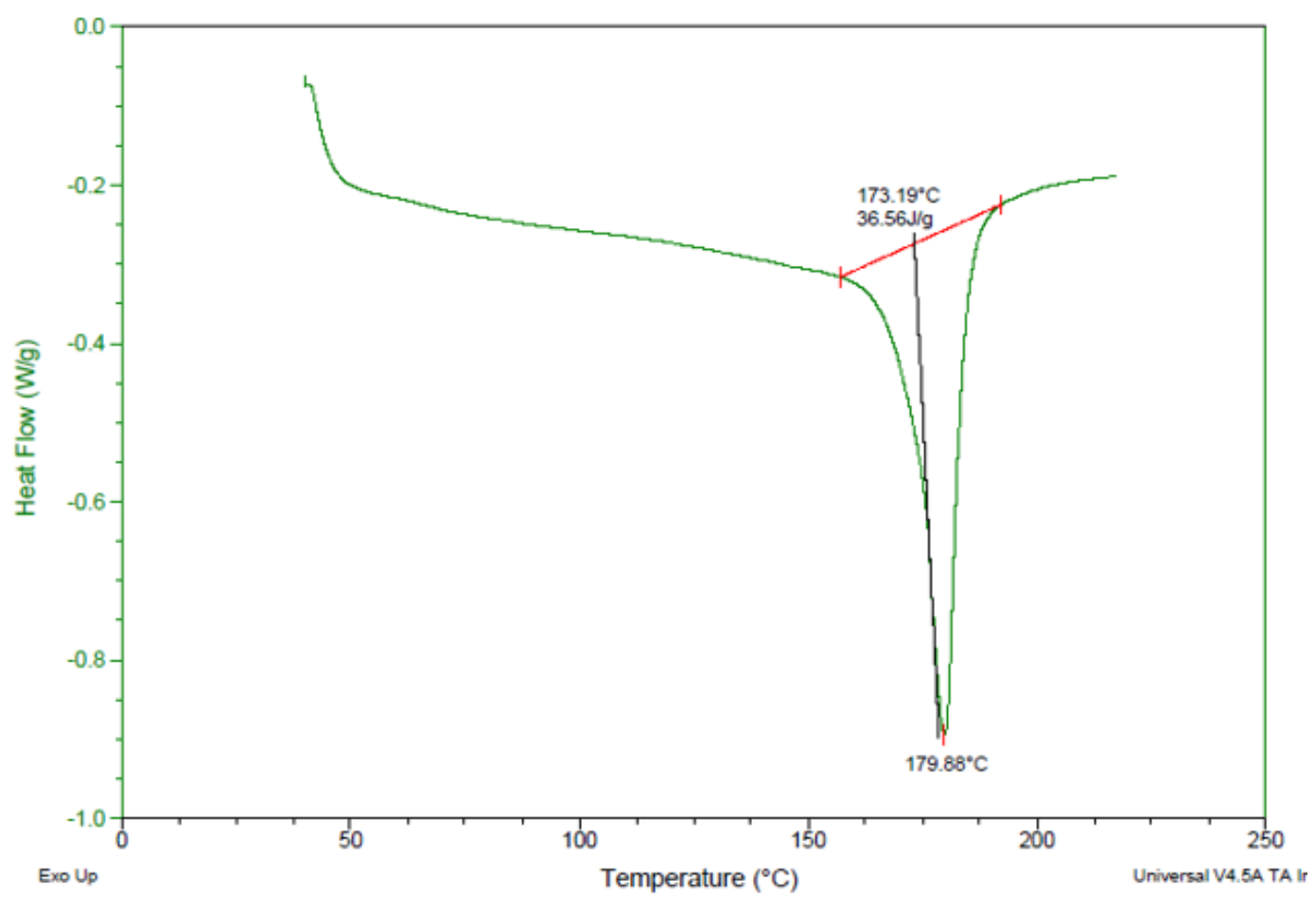

Figure 7. It shows the DSC curve for the treated kenaf fiber composite with a fiber weight fraction of $40 \%$

In order to analyze the effect of treatment on macro mechanical of the composite, two composites were made with a fiber weight fraction of $40 \%$, one contained treated fibers and the other had untreated kenaf fiber. All other parameters were left constant. DSC was conducted on the composite to analyze if there was any difference prior to testing. The analysis was conducted in nitrogen environment with a ramp up rate of $10^{\circ} \mathrm{C}$. Figures 6 and 7 show the DSC results for the treated and untreated kenaf fiber composite. The fiber treatment does not have any major thermal changes to the PA12. One key difference is the moisture uptake in the composite arising from the fibers. There is a transition noted in the $60^{\circ} \mathrm{C}$ to $100^{\circ} \mathrm{C}$ range in the DSC curves in figure 6 with the untreated fiber composite which is not evident in figure 7 . This transition correlates to the water being removed from the composite in the DSC samples. The main contributor to water uptake in the composites is the fibers, in particular the treatment of fibers, as the matrix is the same in both cases. The main reason the water uptake is lower in the case of treated fibers is that the alkali treatment reduces the number of active hydrophilic hydroxyl groups in the fibers thus making the fiber less hydrophilic as compared to the untreated fiber [25-27].

\section{Results and Discussion}

All samples used for testing were cut as per ASTM standards. Tensile and flexure samples were made based on ASTM D3039 and ASTM D790 respectively. The fractured sample was used for failure mode analysis using a
Scanning Electron Microscope (SEM).

\section{Mechanical Characterization}

\section{Tensile Test}

The samples were tested in a 22 kip load frame with an external extensometer to obtain strain values to calculate the modulus. All the samples were tested with a rate of $1 \mathrm{~mm} / \mathrm{min}$. In order to see the difference in the performance of the fibers due to the treatment method adopted, samples were made for tensile testing using treated and untreated fibers. The comparison of its tensile strength and modulus is shown in figures 8 and 9 respectively.

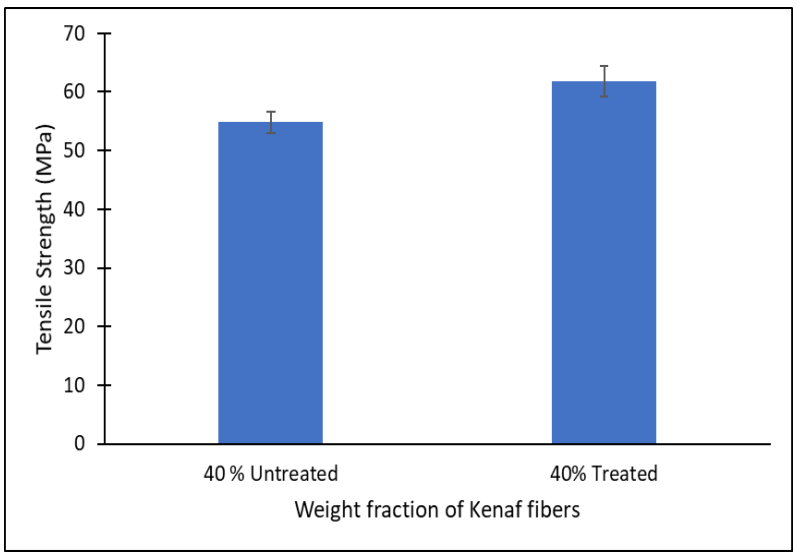

Figure 8. It compares the tensile strength for a composite with untreated and treated kenaf fibers with a fiber weight fraction of $40 \%$ 


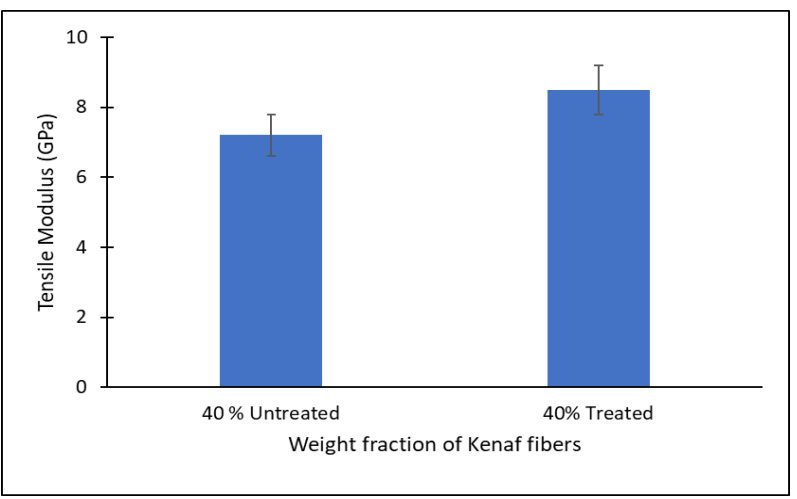

Figure 9. It compares the tensile modulus for a composite with untreated and treated kenaf fibers with a fiber weight fraction of $40 \%$

Based on the tensile data above, there is an increase of $13 \%$ and $18 \%$ in the tensile strength and modulus of a composite with treated kenaf fibers as compared to the untreated fibers. This increase can be attributed to the alkali treatment of the fibers as all the other parameters are constant. Based on the SEM images shown in figure 2, the surface roughness coupled with the striations on the fiber surface has led to better bonding and thus a better and stronger interface between the fibers and the matrix. The standard deviation for the two sets is comparable indicating that the consistence of the testing is similar. Based on this result, the rest of the analysis conducted was done only on treated kenaf fibers as they performed better than the composites with untreated kenaf fibers.

The tensile strength and modulus for the kenaf/PA12 composites at various weight fractions are shown in figures 10 and 11 respectively. Neat PA12 samples were also tested and served as a baseline data point.

The data show a trend of increasing its tensile properties with an increase in fiber content. There is an increase of $13 \%$ and $41 \%$ for the 50 and 60 weight fraction with respect to $40 \%$ weight fraction. A similar trend is seen in its tensile modulus values as well as shown in figure 11 . There is an increase of $5 \%$ and $20 \%$ in modulus for 50 and 60 weight fraction as compared to $40 \%$ respectively.

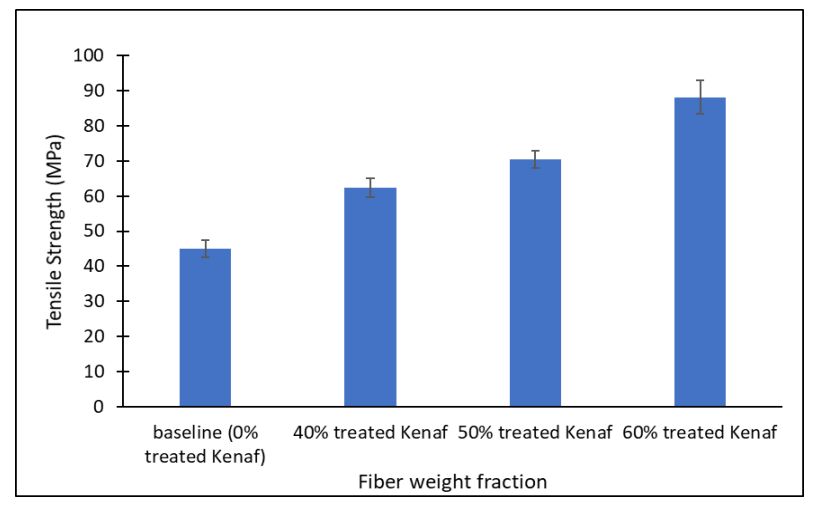

Figure 10. It compares the tensile strength for Kenaf fiber PA12 composite at various weight fractions

The $60 \%$ weight fraction samples show more inconsistency in data as compared to the other two weight fractions due to the amount of fibers present. This is shown in the higher standard deviation as compared to the rest of the samples tested. A combination of fiber clumping and dry fibers leads to inconsistent interface formed throughout the composite. This leads to inconsistent performance during testing as seen in its standard deviation. This behavior confirms previous studies done on the fact that beyond a particular point, the composite does not behave well when making fiber preforms using hydroentanglement. Those studies show that clumping in the preforms and fiber web density play a role in making underperforming composites at higher weight fraction [22, 23].

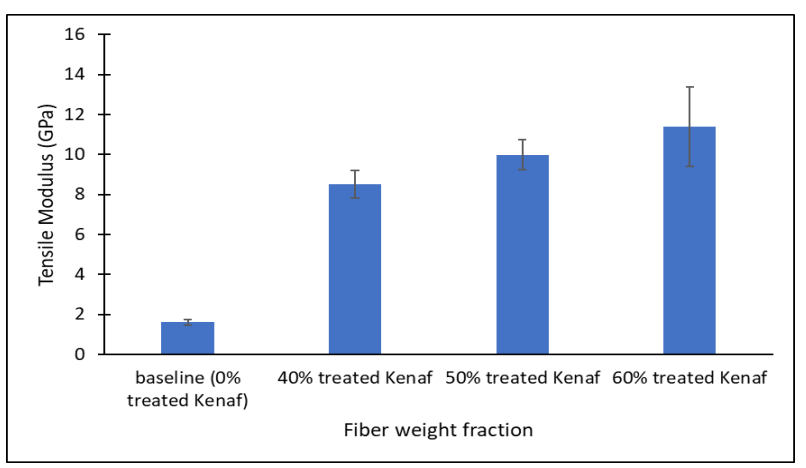

Figure 11. It compares the tensile modulus for Kenaf fiber PA12 composite at various weight fractions

\section{Flexure Test}

The samples were prepared as per ASTM D790 and tested on a $12 \mathrm{kip}$ load frame. 3 point bending test was conducted on all the specimens with a rate of $2 \mathrm{~mm} / \mathrm{min}$. The flexure strength and modulus are shown in figures 12 and 13 respectively. Neat PA12 is used as a baseline. The flexure strength has a trend similar to the tensile properties. The flexural properties increase with an increase in fiber content. There is an increase of $41 \%$ and $83 \%$ in its flexure strength properties for 50 and 60 fiber weight percent as compared to the 40 weight percent respectively. There is a similar trend in the flexural modulus results as well. There is an $81 \%$ and $218 \%$ increase in its modulus when compared to the 40 fiber weight percent.

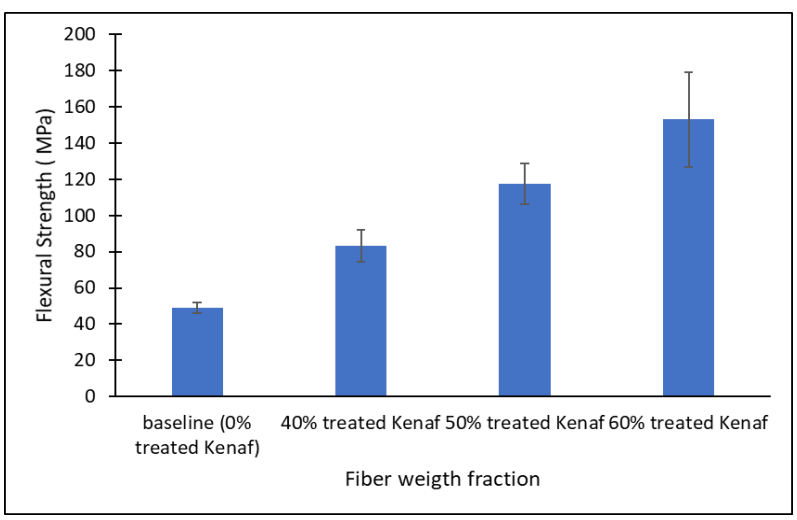

Figure 12. It compares the flexure strength for Kenaf fiber PA12 composite at various weight fractions 


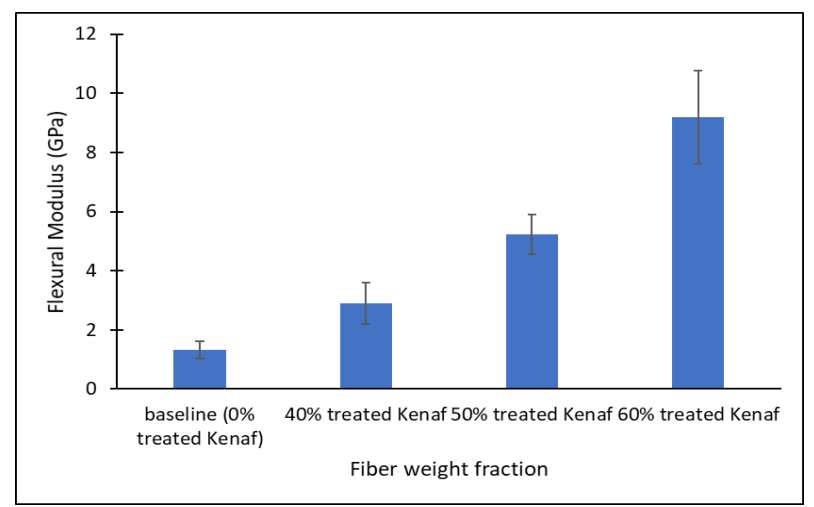

Figure 13. It compares the flexure Modulus for Kenaf fiber PA12 composite at various weight fractions

The flexural strength and modulus is higher than tensile strength and modulus across the board. But also the standard deviation is high. One explanation for this is the test setup. Since it is a 3-point bend test, the load applied is essentially a point load in the force body diagram. As a result, the morphological makeup of the composite under the applied load is critical. As the fiber weight fraction increases, the variability in the interface between the fiber and matrix increases. As a result, the individual samples tested largely depend on whether the location of defects such as clumping, dry fibers etc. is present under the applied load.

The samples failed on the tensile side of the sample i.e. the bottom side of the sample. This is a typical mode of failure in discontinuous fiber composites [18,21]. The neat PA12 had a lot of crazing before failure occurred. While there was some crazing seen in the samples with a fiber
$40 \%$ weight fraction, this crazing was not seen with higher weight fraction. The 60 percent samples are the most inconsistent owing to clumping of fibers leading to inconsistent wet-out similar to the trend seen in the tensile samples. A summary of the mechanical test data is provided in table 1.

Figure 14 showed the fractured surface of the composites made using untreated and treated kenaf fiber composites. While there is fiber pull-out in both cases, the highlighted area in figure 12 (a) shows clumping of fibers. These clumps can be seen all over the composite with untreated kenaf fibers. The reason for this is the fluff, wax that typically holds these fibers are not removed. As a result, there are many dry fibers in the clump as the PA12 is too viscous to flow in between the clumps. This leads to many fibers having no interface with the matrix and thus leads to a lot of fiber pulled during failure. Fiber pull-out is typically seen on fractured surface with weak interfaces [1, 3]. Figure 12(b) on the other hand, shows that chemical treatment opened multiple reaction sites with the cellulose which led to a better interface. This is seen with a much lower number of clumps in the fractured surface. Apart from striations on the fibers, the excess fluff and wax is also removed from the surface of fibers which reduces the fibers ability of clump. While there was fiber pull-out, the over failure mode was a mix to fiber breakage and pull-out which is indicative of a better interface as compared to the untreated kenaf fiber composites. This morphological difference in the interface and reduction of fiber clumps translates to better macro mechanical properties as shown in figures 6 and 7 respectively.

Table 1. Summary of mechanical testing results

\begin{tabular}{ccccc} 
& \multicolumn{2}{c}{ Tensile } & \multicolumn{2}{c}{ Flexure } \\
\cline { 2 - 5 } Sample & Strength (MPa) & Modulus (GPa) & Strength (MPa) & Modulus (GPa) \\
\hline 0 wt\% Kenaf fibers + 100 wt\% PA12 & $45 \pm 2.5$ & $1.61 \pm 0.14$ & $48.4 \pm 3.2$ & $1.32 \pm 0.3$ \\
$40 \mathrm{wt} \%$ Kenaf fibers + 60 wt\% PA12 & $62.4 \pm 2.7$ & $8.5 \pm 0.7$ & $83.36 \pm 8.9$ & $2.87 \pm 0.67$ \\
$50 \mathrm{wt} \%$ Kenaf fibers + 50 wt\% PA12 & $70.5 \pm 1.43$ & $9.98 \pm 0.74$ & $117.62 \pm 11.31$ & $5.23 \pm 0.67$ \\
$60 \mathrm{wt} \%$ Kenaf fibers + 40 wt\% PA12 & $88.2 \pm 3.8$ & $11.4 \pm 1.98$ & $153.05 \pm 26.34$ & $9.16 \pm 1.58$ \\
\hline
\end{tabular}

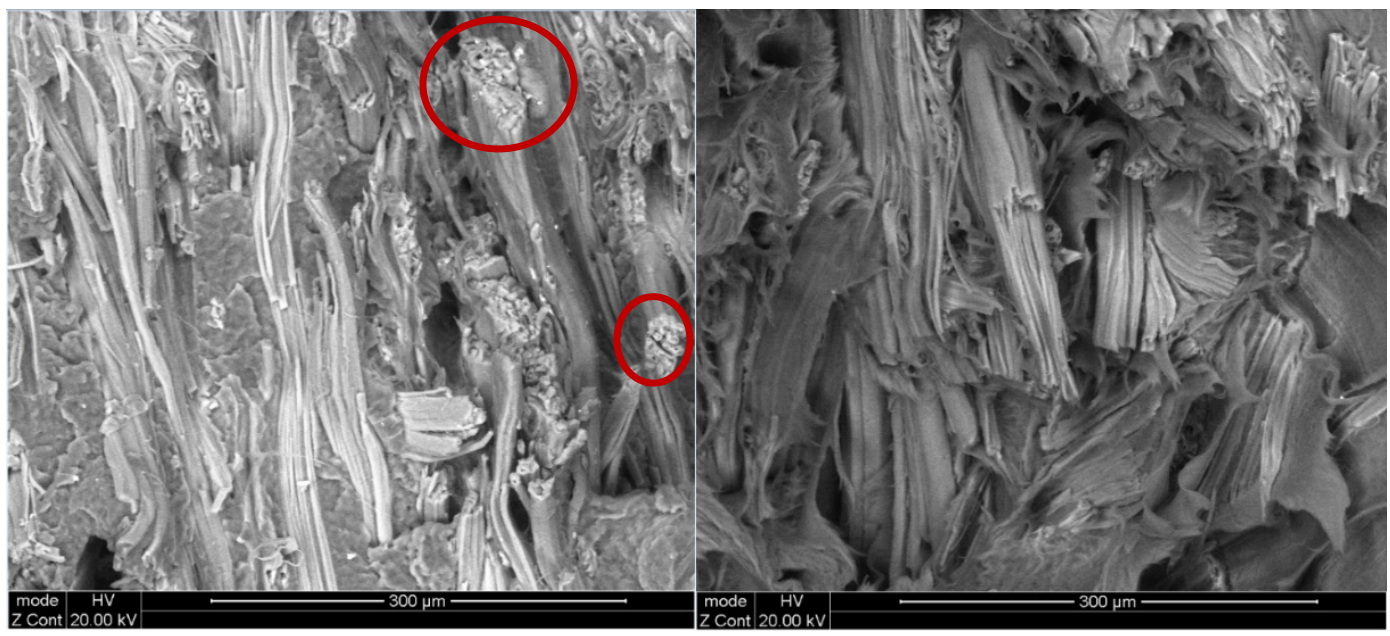

(a)

Figure 14. (a) shows the fractured surface of the $40 \mathrm{wt} \%$ untreated kenaf fiber/PA12 composite; (b) shows the fractured surface of the $40 \mathrm{wt} \%$ treated kenaf fiber/ PA12 composite 

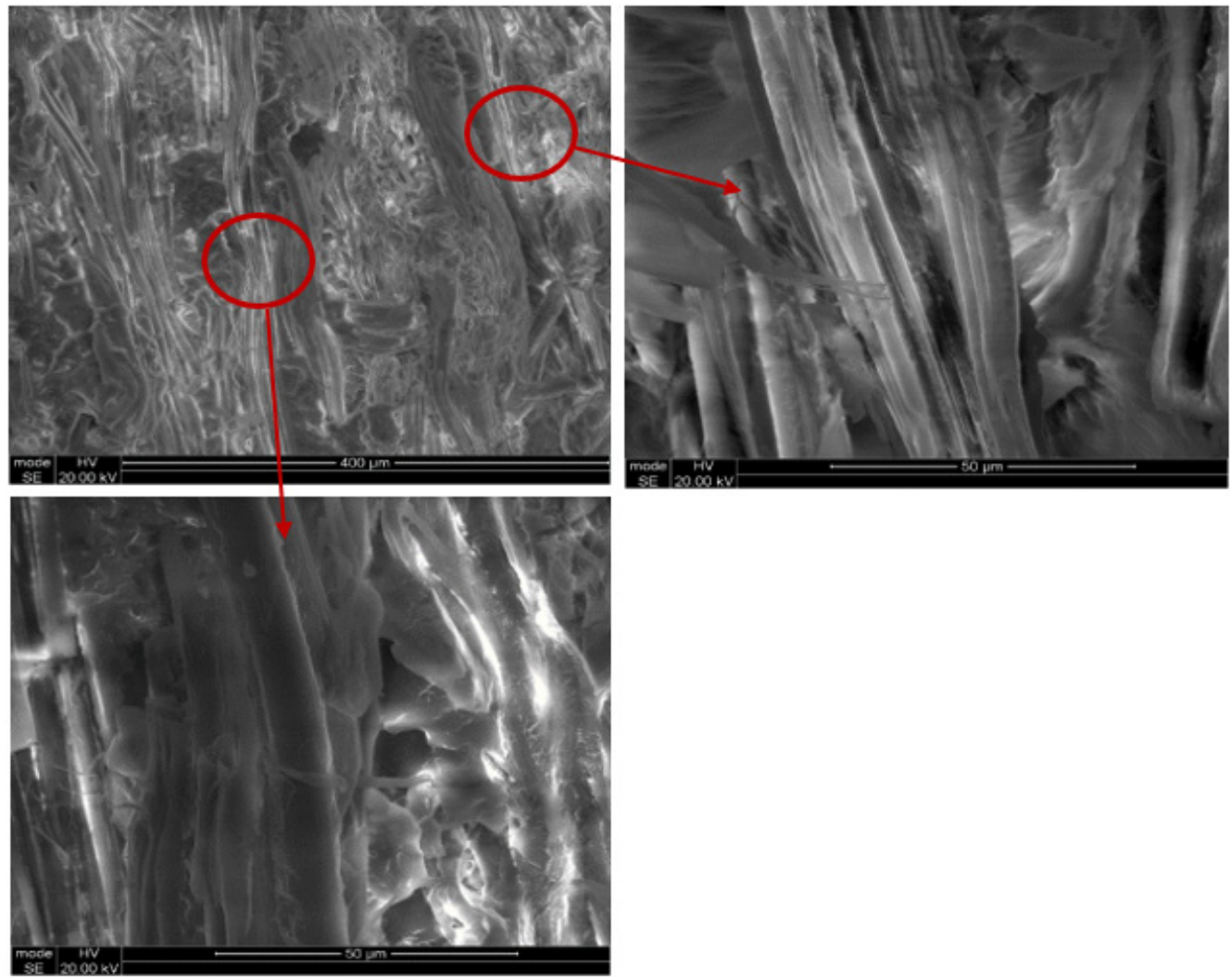

Figure 15. It shows the SEM images of $50 \mathrm{wt} \%$ kenaf/PA12 composite at, (a) 300x magnification; (b) 1500x magnification showing bonding sites; (c) 1500x magnification of an area with some fiber bundling

\section{Morphological Characterization}

SEM images were also taken of the 50 weight percent sample to see the fiber wet out and are shown in figure 15 below. The increase in the standard deviation seen in the $50 \%$ weight fraction samples made it a good candidate to study why this variation in properties was higher. Figure 15 (a) shows the fractured surface of the composite. While there is a good bonding between the fibers and the matrix overall, there are zones where there has been fiber pull-out leading to the appearance of voids on the surface. There are also a lot of individual fibers coated well with resin which was seen in the case of Figure 14 (b) as well.

A close up of the fractured surface shows the bonding between the fibers and the matrix as shown in figure 15 (b). Figure 15 (c) shows the close up of a clump seen on the fractured surface. While the fibers on the outside of the clump have bonded with the matrix, the fibers in the clump can be expected to be dry. These clumps will have a similar look to the clumps noticed in figure 14(a). One of the reasons for the fiber pull-out can be attributed to the clumping of fibers during the hydroentanglement process. As the fiber web density increases due to the addition of more fibers, the tendency to form clumps also increases [21]. This clumping seemed to leave a few fibers with minimal bonding with the resin leading to a poor interface in certain section of the composite. The variable nature of the fiber matrix interface across the composite leads to higher variability in the mechanical properties of the panel as seen in the mechanical properties.

\section{Conclusions}

Discontinuous kenaf fibers with one inch length were successfully made into fiber preforms using hydroentanglement and molded with nylon 12 (PA12) to make composites of varying fiber weight fractions. Thermal characterization of the kenaf fibers showed onset of degradation at around $205^{\circ} \mathrm{C}$ which is in agreement with literature. DSC was carried out on the PA12 to identify its melting point $\left(178^{\circ} \mathrm{C}\right)$ and set process parameters. The molding temperature was set to $185^{\circ} \mathrm{C}$ based on the thermal characterization. DSC results of the $40 \%$ weight fraction composite with treated and untreated fibers showed a transition between $60^{\circ} \mathrm{C}$ and $100^{\circ} \mathrm{C}$ in the case of the untreated fiber composite. This was due to the fact that the treated fibers were less hydrophilic as compared to the untreated fibers due to the alkali treatment.

Mechanical characterization showed an increase in its tensile and flexure properties of the kenaf fiber composite as compared to the neat PA12. There was also an increase in its mechanical properties with an increase in fiber weight fraction. There was an increase in standard deviation of the results as the fiber weight fraction was increased to $60 \%$. The reason for this was the clumping seen in the preforms 
leading to dry fibers in the composite.

SEM images of the treated and untreated kenaf composite showed that the fiber matrix interface was more prominent and consistent in the case of treated kenaf fibers. SEM analysis of the $50 \%$ fiber composite showed a mixed mode of failure between some sheared fibers and some fiber pull-out. There were some dry fibers seen which is a result of the fibers clumping during the hydroentanglement process.

The successful combination of kenaf fibers with PA12 through strong mechanical properties shows the feasibility of this approach extended to other natural fibers to produce high performance PA12 based natural fiber composites. The major application of this composite is for tertiary structural components in the automotive industry.

\section{REFERENCES}

[1] U. Vaidya, S. Brahma, B. Willis, S. Pillay, Comparison of wet laid to other discontinuous processed carbon fiber thermoplastic composites, CAMX, Dallas, (2014).

[2] S. Brahma, H. Ning, S. Pillay Comparison and characterization of discontinuous carbon fiber liquid-molded nylon to hydroentanglement/ compression-molded composites, Journal of Thermoplastic Composite Materials (2019).

[3] H.M. Akil, M.F. Omar, A.A.M. Mazuki, S.Safiee, Z.A.M. Ishak, A. Abu Bakar, Kenaf fiber reinforced composites: A review, Materials \& Design 32(8-9) (2011) 4107-4121.

[4] A. Bledzki, J. Gassan, Composites reinforced with cellulose based fibers, Prog Polym Sci 24 (1999) 221-274.

[5] L.A. Pothan, Z. Oommen, S. Thomas, Dynamic mechanical analysis of banana fiber reinforced polyester composites, Composite Science Technology 63 (2003) 283-293.

[6] A.Hart, J. Summerscales, Advanced Materials for a Greener World,, 3rd International Conference on Natural Fibers, Procedia Engineering, Braga, Portugal, June 2017, pp. 269275.

[7] N.P.J. Dissanayake, J. Summerscales, Life Cycle Assessment for natural fibre composites, Chapter 8: Green Composites from Natural Resources, in: V. Thakur (Ed.), Life Cycle Assessment for natural fibre composites, Taylor and Francis Group LLC, USA, USA, 2014, pp. 157-186.

[8] Bismarck A, S. Mishra, Lampke T., Plant fibers as reinforcement for green composites CRC Press, Boca Raton, Florida, 2005.

[9] M.K. Gupta, R.K. Srivastava, H Bisaria, Potential of jute fibre reinforced polymer composites: a review, International Journal of Fiber and Textile Research 5(3) (2015) 30-38.

[10] K. Werner, L. Pommer, M. Broström, Thermal decomposition of hemicelluloses, Journal of Analytical and Applied Pyrolysis 110 (2004) 130-137.

[11] F. Roig, E. Dantras, J. Dandurand, C. Lacabanne, Influence of hydrogen bonds on glass transition and dielectric relaxations of cellulose, Journal of Physics D: Applied Physics 44(4) (2011) 8pp.

[12] G. Mehta, A. Mohanty, M. Misra, L. Drzal, Effect of novel sizing on the mechanical and morphological characteristics of natural fiber reinforced unsaturated polyester resin based bio-composites, Journal of Material Science 39 (2004).

[13] D. Rouison, M. Sain, M. Couturier, Resin transfer molding of natural fiber reinforced composites: cure simulation, Composite Science Technology 64 (2004) 629-644.

[14] G.V. Salmoria, J.L. Leite, L.F. Vieira, A.T.N. Pires, C.R.M. Roesler, Mechanical properties of PA6/PA12 blend specimens prepared by selective laser sintering, Journal of Polymer Testing 31(3) (2012) 411 - 415.

[15] Edeerozey, H.M. Akil, A. Azhar, M. Ariffin, Chemical modification of kenaf fibers, Materials letters 61 (2007) 2023-2025.

[16] Y.H. Han, S.O. Han, D. Cho, H.I. Kim, Kenaf/polypropylene biocomposites: effects of electron beam irradiation and alkali treatment on kenaf natural fibers, Journal of composite interfaces 14 (2007) 559-578.

[17] M.S. Huda, L.T. Drzal, A.K. Mohanty, M. Misra, Effect of fiber surface-treatments on the properties of laminated biocomposites from poly (lactic acid) (PLA) and kenaf fibers, Journal of Composite Science Technology 68 (2008) 424-432.

[18] J. George, M. Sreekala, S. Thomas, A review on interface modification and characterization of natural fiber reinforced plastic composites, Polymer engineering Science 41 (2001) $1471-1485$.

[19] X. Li, L.G. Tabil, S. Panigrahi, Chemical treatments of natural fiber for use in natural fiber-reinforced composites: a review, Journal of Environmental Polymer Degradation 15 (2007) 25-33.

[20] S. Ochi, Mechanical properties of kenaf fibers and kenaf/PLA composites, Mechanical Materials 40 (2008) 446-452.

[21] S. Brahma, S. Pillay, H. Ning, V. Thomas, Characterization of discontinuous carbon fiber liquid molded PA-6 composites via strategic placement of additional reinforcements, Journal of Reinforced Plastics and Composites 37(22) (2018) 1335 - 1345.

[22] J Wollinga, M Schmiega, Frank Manisa, K. Drechslerb, Nonwovens from Recycled Carbon Fibers - Comparison of Processing Technologies, Procedia CRIP 66 (2017) 271 276.

[23] N. Vaidya, B. Pourdeyhim, D. Shiffer, The Manufacturing of Wetlaid Hydroentangled Glass Fiber Composites for Industrial Applications, Masters Thesis, North Carloina State University, Dept of Textile Technology Management (2002)

[24] Y. Lu, Mechanical Properties of Random Discontinuous Fiber Composites Manufactured from Wetlay Process, Masters Thesis, Virginia Polytechnic Institute and State University, Department of Mechanical Engineering (2002)

[25] B.M Reddy, Y.V.M Reddy, B.C.M Reddy, Effect of Alkali Treatment on Mechanical, Water Absorption and Chemical Resistance Properties of Cordia-Dichotoma Fiber Reinforced Epoxy Composites, International Journal of 
Applied Engineering Research 12(6) (2018) pp. 3709 - 3715

[26] G. Goud, R.N Rao, Effect of fibre content and alkali treatment on mechanical properties of Roystonea regia-reinforced epoxy partially biodegradable composites,
Bulletin of Materials Science, 34 (7) (2011) pp. 1575 - 1581

[27] A. Gupta, Synthesis, chemical resistance, and water absorption of bamboo fiber reinforced epoxy composites. Polymer Composites, 37(1) (2014), pp. 141-145. 